\title{
First Year Student Perception and Experience of Online Topographical Anatomy Laboratory Classes using Zoom Technology during the COVID-19 Pandemic
}

\author{
Rudi Klein $^{\mathrm{ab}}$, Chiara Tomassoni ${ }^{\mathrm{a}}$, Gayathri Rajaraman ${ }^{\mathrm{a}}$, Maxwell Winchester ${ }^{\mathrm{a}, \mathrm{c}, \mathrm{d}}$, Norman \\ Eizenberg ${ }^{\mathrm{e}}$, and Puspha Sinnayah ${ }^{\mathrm{a}, \mathrm{b}}$ \\ Corresponding author: Rudi Klein (rudi.klein@vu.edu.au) \\ ${ }^{a}$ First Year College, Victoria University, PO Box 14428, Melbourne VIC 8001, Australia \\ ${ }^{b}$ Institute for Health and Sport, Victoria University, Melbourne, VIC 8001, Australia \\ 'Institute of Sustainable Industries and Liveable Cities, Victoria University, Melbourne VIC 8001, Australia \\ ${ }^{\mathrm{d} C o p e n h a g e n ~ B u s i n e s s ~ S c h o o l, ~ S o l b j e r g ~ P l a d s, ~ F r e d e r i k s b e r g ~ 2000, ~ D e n m a r k ~}$ \\ ${ }^{\mathrm{e} M e l b o u r n e}$ Clinical School, University of Notre Dame, Werribee, Melbourne, Australia
}

Keywords: COVID-19 lockdown, e-learning, topographical anatomy laboratory, active learning

\begin{abstract}
During semester one of 2020, the units 'Functional Anatomy of the Trunk' and 'Functional Anatomy of the Limbs' which focus on human topographical anatomy were re-designed into an online delivery format and taught remotely in response to the COVID-19 lockdown. It was expected that the move to remote teaching would negatively impact student perception and learning experience, in particular that of the cadaver-based laboratory work. The aim of this study was to investigate whether the replacement of traditional face-to-face cadaver-based anatomy laboratories with an online version using digital anatomy resources and Zoom technology as the communication platform would achieve comparable student learning experience and outcomes. First Year Students $(n=69)$ enrolled in these units were invited to participate in this study and were asked at the conclusion of each unit to complete an anonymous opinion-based survey via Qualtrics. The Qualtrics data, student grades and Learning Management System (LMS) statistics were analysed. Results indicate that student perception of the online gross anatomy laboratory learning was positive and that it had complemented their learning. Most students agreed that as a visual learning resource, it provided an improved understanding of anatomy and helped with the application of anatomical knowledge. Interestingly, student performance showed a similar range of marks compared with previous years. However, students strongly agreed that the online 2D learning experience had significant limitations when compared to live use of cadavers in laboratories.
\end{abstract}

\section{Introduction}

\section{The COVID crisis}

Almost overnight, COVID-19 transformed how we live, work, play, and learn. Higher Education providers were among those affected first and hardest hit; campuses across the world including Australia were shutdown, international students were unable to enter the country, and there was the need for an immediate shift from face-to-face to online learning (Evans et al., 2020; Pather et al., 2020; Longhurst et al., 2020; Iwanaga et al., 2021). 


\section{Context for Universities}

Higher education providers all over the world, to the tune of more than 188 countries, have been impacted by this global pandemic. This equates to more than $90 \%$ of the world's student population from Primary to Tertiary (UNESCO, 2020).

Universities were quick to respond, quickly moving from face-to-face teaching, to teaching synchronously remotely or asynchronously online (Ali, 2020; Burki, 2020). Educators were now looking to redesign their units and to find answers to the many challenges that have come with distance learning format, especially given the increased burnout and lack of student engagement when universities offered only asynchronous lecture recordings (Chen, Kaczmarek \& Ohyama, 2020; Pather et al., 2020).

A review of medical schools teaching anatomy in England and Ireland demonstrated the rapid shift from in person to the online learning environment, substituting the cadaver-based learning with digital anatomy (Longhurst et al., 2020). Using a SWOT (strength, weakness, opportunity and threat) analysis, Longhurst et al. (2020) demonstrated a surprising commonality in the online teaching approach and type of resources used across the 14 different participating anatomy teaching universities in the United Kingdom and Republic of Ireland. This sudden and drastic shift was also reflected in Australia and New Zealand, demonstrating the suspension of the human body donor program in some medical schools, lectures now replaced by prerecorded concept videos, and practical sessions scheduled asynchronously and/or synchronously using multimedia resources, either with or without live streaming tutor support (Pather et al., 2020).

While many universities switched from live lectures to asynchronous recorded lectures, this was not an option in Victoria University's (VU) active learning block model approach, which features 3 hour active learning workshops (McCluskey, Weldon, \& Smallridge, 2019). As a result, most units were offered synchronously and the timetabled period and active learning activities were modified to a suitable remote delivery format. A distinctive feature of the study of topographical anatomy at VU is the use of prosected cadavers in the anatomy laboratory. While the cadaver laboratory has always been a feature which attracted students to the study of anatomy, it now presented a unique challenge in that the state law of Victoria (Government of Victoria, 1982) prohibits the filming and or dissemination of cadaveric material (without prior donor consent) in any form whatsoever, thereby making it impossible to film existing teaching material which could then be quickly uploaded and used as resource in the online anatomy laboratories.

During the $1^{\text {st }}$ semester of 2020 the units 'Functional Anatomy of the Trunk' and 'Functional Anatomy of the Limbs' were quickly re-designed into a remote delivery format. The curriculum of these units focusses on topographical anatomy of the human trunk and limbs. The unique attributes of these units make them of interest for this case study. While some units transfer easily to a remote learning format, here the traditional face-to-face cadaver-based laboratory learning always considered a corner stone of anatomical education, represented a change that was considered greater compared with other units.

The content of the new online laboratory sessions used digitised cadaveric images, together with a suite of web-based interactive multimedia simulation resources, such as, An@ tomedia Online, Acland's Atlas of Human Anatomy, Thieme and AnatomyTV. These simulation resources include 3D digital images and interactive anatomical models and are also widely used at other Universities teaching anatomy (Pather et al., 2020; Longhurst et al., 2020). 
The entire laboratory curriculum was re-written and replaced with a suitable format that enables it to be used in synchronous Zoom (Zoom Voice Communications Inc, San Jose, CA) sessions. The curriculum content and contact hours remained the same. All synchronous online laboratory "Zoom" sessions were live streamed and tutor supported.

\section{Assessment}

Summative assessment was utilised in which each live streamed Zoom laboratory session required the completion of an assessable laboratory worksheet. The total weighting of the laboratory component was $40 \%$ of the total mark for the unit. The worksheet consisted of; short written response questions, identification questions, single answer response questions, fill in a table questions and higher order synthesis, analyse and construct questions. The worksheet activity questions were intentionally matched with the content topic within the simulation programs. A feature of our online assessment work is the increased time needed and difficulty required to using a computer keyboard to type in the answers. The remaining $60 \%$ of the mark consisted of summative assessments based on the theory taught in workshops. All assessments occurred online, and therefore were classified as open-book assessments.

\section{Unique setting of Victoria University}

\section{The block teaching model}

Functional Anatomy of the Trunk and Limbs is taught within the First Year College (FYC) incorporated within the framework of the "block teaching model" which was adopted at the beginning of 2018 (McCluskey et al., 2019; 2020). The block teaching model is a timecompressed method of intensive teaching in which the entire curriculum of a unit is taught and assessed over 4 weeks, and in which lectures and tutorials are replaced with workshops and face-to-face laboratories that follow sequentially. This new block teaching model (BTM) provided the overarching framework into which the new online teaching format had to fit (McCluskey et al., 2019; 2020). This format of teaching is not entirely unusual in the discipline of anatomy (Hubbard, Miller, \& Olson, 2005; Larkin \& McAndrew, 2013; Ganske, Su, Loukas, \& Shaffer, 2006; Morris \& Chirculescu, 2021)

\section{Remote synchronous teaching}

The teaching of gross anatomy has changed dramatically over the years. It has become increasingly important to provide a blended learning environment, which has student centered learning activities built to facilitate laboratory engagement (Flynn et al., 2021). It is without doubt that applying this flexibility in how we teach, such as mixed method of teaching and learning in anatomy during the current crisis is what is clearly needed (Flynn et al., 2021). Short segments of video clips from Acland's Atlas of Human Anatomy (8-9 segments of 10-30 minutes in length) were embedded in the learning activities and used to present dissection specimens to our students (Acland, 2013).

Although studying real cadaver bodies provides an unparalleled means of teaching gross anatomy and is seen as an essential ingredient to anatomy education, it was not an option during the COVID-19 lockdown combined with social distancing requirements (Flynn et al., 2021). The increasing availability of Computer Aided Learning (CAL) software has been increasingly used to supplement and support the teaching of anatomy (Klein et al., 2019). The resources used as substitutes for the cadaver-based laboratory learning were freely accessible anytime, at no cost to all students, and available through the University library portal. The design of the 
worksheets which interfaced with the various simulation programs, were supplemented by a digitised cadaveric image library and plastic models and were tailored to the learning outcomes to maximise active learning interaction between the student and the required content.

Our e-learning approach consisted of not just making available another resource for students to use online, rather we intentionally used suitable computer based online programs previously shown to be applicable and helpful to students in bridging their understanding between theory and laboratory practice (Klein et al., 2019). The design and implementation of the anatomy laboratory activities were based on a model of continuous improvement that involves review and refinement based on student feedback and evaluation after each online mode of block teaching (Pather, 2015), with learning activities designed to be learner engaging, contextual and clinically relevant.

\section{Aims and Research Questions}

To investigate whether the replacement of traditional face to face cadaver-based anatomy laboratories with online laboratory classes using Zoom technology supplemented with online digital anatomy simulation programs, achieved comparable student learning outcomes and learning experience.

\section{Materials and Methods}

This study was approved by the Ethics Committee at Victoria University (HRE-17-192). Informed consent was obtained from all students and participation proceeded on a voluntary basis only.

Functional Anatomy of the trunk (unit code RBM1100) is a first year, first semester unit and Functional Anatomy of the Limbs (unit code RBM1200) is a first year, second semester unit. The curriculum deals with the topographical anatomy of the human trunk and limbs.

This study used four different online simulation programmes designed for the study of topographical anatomy: "Aclands Atlas of Human Anatomy" (Acland, 2013), An@tomedia Online (Eizenberg et al., 2019), AnatomyTV (Primal-Pictures, 2019) and Thieme (Gilroy et al., 2019), and a digitised cadaveric image library, together with plastic models when appropriate.

Each 2-hour online laboratory involved the utilisation of interactive multimedia programs including videos and interactive e-leaning modules, in 2-5 minute segments. Between each segment, was time for live discussion facilitated by the tutor, and time for students to complete worksheet questions.

Zoom (Zoom Voice Communications Inc., San Jose, CA) was used as the communication platform, and the whiteboard function within the Zoom program supplemented with a WACOM (Japan) tablet, to promote interactivity.

\section{Survey}

An anonymous opinion-based survey (via Qualtrics) was conducted at the end of each of 6 consecutive anatomy teaching blocks of semester 1 and semester 2 in 2020. It was sent to all students enrolled in Functional Anatomy of the Trunk and Functional Anatomy of the Limbs. 
The survey consisted of 43 closed questions and 8 open-ended questions. The survey was distributed via email, and or VU collaborate (VU's Learning Management System) and embedded in the Qualtrics software. All First Year Students $(n=218)$ enrolled in Human Biomedicine /Bioscience degree (HBBM, HBBS) were invited at the conclusion of the unit to complete the anonymous opinion-based survey via Qualtrics.

The survey asked students to assess the quality and utility of each online anatomy laboratory. The opinion-based survey ranked the value of each question category in order of 1 to $5,(1-$ strongly disagree to 5 - strongly agree) with 69 respondents (or 31\%) from 218 students enrolled. Given the small population and sample size for the study, statistical analyses are limited, and largely descriptive statistics are utilised. With the sample size achieved in this study the power is 0.8 at $\mathrm{p}<0.05$.

The open-ended survey questions were grouped into the following question categories: questions relating to: (1) The online learning environment, (2) The online laboratory tutor, (3) The learning experience while in the online laboratory itself, (4) The perceived learning gain obtained from the online anatomy laboratory, (5) The overall impression of the learning experience of each online laboratory.

Once all data had been collected, they were exported from the online survey into SPSS where descriptive data were collated and analyses were conducted. In addition, student academic performance data were obtained from the LMS. Academic performance is represented as a mean $+/-\mathrm{SD}$, and an independent two-sample t-test was used to analyse performance between semesters and years.

\section{Results}

The quantitative results from the survey are shown in Tables 1 to 5. The survey is divided into 5 question themes:

1. The online learning environment

2. The live stream online laboratory tutor

3. The learning experience while attending the online laboratory itself

4. The perceived learning experience outcomes after having attended the online anatomy lab

5. The overall impression of learning experience of the online laboratory.

The data are shown as a $\%$ of the total number of responders for Tables 1-5.

\section{Theme 1. The online laboratory learning environment}

The survey results show that the laboratory makes an important contribution to student learning (71\%), providing an environment is conducive to their learning (77\%), and with the aid of digital cadaver resources it aided student understanding of anatomy $(71 \%)$. 
Table 1: The online laboratory learning environment

\begin{tabular}{|c|c|c|c|c|c|c|}
\hline & & Stron & disagre & & trongly & \\
\hline & & 1 & 2 & 3 & 4 & 5 \\
\hline Q1a & The lab makes important contribution to my learning & $3 \%$ & $3 \%$ & $23 \%$ & $43 \%$ & $29 \%$ \\
\hline Q1b & The lab environment is conducive to my learning & $3 \%$ & $3 \%$ & $17 \%$ & $60 \%$ & $17 \%$ \\
\hline Q1c & The cadaver photos aided my learning & $0 \%$ & $6 \%$ & $23 \%$ & $40 \%$ & $31 \%$ \\
\hline Q1d & The online lab sessions were concise and focused & $3 \%$ & $14 \%$ & $23 \%$ & $40 \%$ & $20 \%$ \\
\hline Q1e & It was easy to locate what I needed to identify & $6 \%$ & $11 \%$ & $26 \%$ & $51 \%$ & $6 \%$ \\
\hline Q1f & Being online was a challenging environment to work in & $0 \%$ & $20 \%$ & $23 \%$ & $34 \%$ & $23 \%$ \\
\hline Q1g & $\begin{array}{l}\text { The } 2 \text { dimensional cadaver diagrams or phots are hard to } \\
\text { work with }\end{array}$ & $3 \%$ & $17 \%$ & $29 \%$ & $\mathbf{3 8 \%}$ & $14 \%$ \\
\hline Q1h & $\begin{array}{l}\text { The online lab was logically organised and appropriate } \\
\text { for each session }\end{array}$ & $6 \%$ & $9 \%$ & $9 \%$ & $\mathbf{5 4 \%}$ & $23 \%$ \\
\hline Q1j & $\begin{array}{l}\text { Not using real bodies makes it hard to appreciate the } \\
\text { relationship between structure and function }\end{array}$ & $0 \%$ & $11 \%$ & $26 \%$ & $40 \%$ & $23 \%$ \\
\hline & & & & & & \\
\hline
\end{tabular}

In contrast, the online environment is itself challenging (57\%) and it is not necessarily an easy medium to locate structures on the 2D cadaver images provided.

Students agreed that the absence of real bodies representing the 3-dimentional nature of anatomy, makes it harder to appreciate the relationship between structure and function (63\%), and the online environment is less interesting and engaging than learning from real bodies $(65 \%)$.

\section{Theme 2: Advantages of live streaming tutor sessions}

From the survey, it is clear that students appreciate the presence of the live stream tutor, in areas such as guidance with key ideas and concepts (77\%), feedback (75\%) and in helping with identifying structures $(80 \%)$. The majority clearly prefer a tutor supported session to that of a self-directed learning experience $(63 \%)$.

Table 2: The online laboratory tutor

\begin{tabular}{|l|l|c|c|c|c|c|}
\cline { 3 - 6 } \multicolumn{2}{c|}{} & Strongly disagree & \multicolumn{3}{c|}{ Strongly agree } \\
\hline Q2a & $\begin{array}{l}\text { The tutor emphasised the key ideas \& concepts before } \\
\text { each session }\end{array}$ & $\mathbf{1}$ & $\mathbf{2}$ & $\mathbf{3}$ & $\mathbf{4}$ & $\mathbf{5}$ \\
\hline Q2b & The tutor is key to understanding the structures presented & $0 \%$ & $6 \%$ & $17 \%$ & $\mathbf{6 3 \%}$ & $14 \%$ \\
\hline Q2c & The tutor provided appropriate feedback & $3 \%$ & $12 \%$ & $12 \%$ & $\mathbf{4 6 \%}$ & $29 \%$ \\
\hline Q2d & $\begin{array}{l}\text { The online lab learning experience with tutor is better } \\
\text { than independent self-directed learning }\end{array}$ & $0 \%$ & $9 \%$ & $29 \%$ & $\mathbf{3 7 \%}$ & $26 \%$ \\
\hline
\end{tabular}

\section{Theme 3: The learning experience while in the online laboratory}

The learning experience while in the online laboratory, was found to range from somewhat engaging (40\% agreeing and 14\% strongly agreeing) towards less engaging (20\% disagreeing and $6 \%$ strongly disagreeing). It nevertheless had the effect of improving student understanding of the topic $(68 \%)$. 
Table 3: While in the online laboratory

\begin{tabular}{|l|l|c|c|c|c|c|}
\cline { 3 - 6 } \multicolumn{2}{l}{ Theme } & Strongly disagree & \multicolumn{3}{c|}{ Strongly agree } \\
\hline Q3a & I found the online lab work engaging & $\mathbf{1}$ & $\mathbf{2}$ & $\mathbf{3}$ & $\mathbf{4}$ & $\mathbf{5}$ \\
\hline Q3b & It helped me further understand anatomy & $6 \%$ & $20 \%$ & $20 \%$ & $\mathbf{4 0 \%}$ & $14 \%$ \\
\hline Q3c & $\begin{array}{l}\text { Less valuable teaching \& learning resource because it is } \\
\text { 2D \& not 3D }\end{array}$ & $3 \%$ & $14 \%$ & $23 \%$ & $\mathbf{3 1 \%}$ & $29 \%$ \\
\hline Q3d & $\begin{array}{l}\text { The content of each online lab session was } \\
\text { comprehensive }\end{array}$ & $0 \%$ & $3 \%$ & $9 \%$ & $\mathbf{6 7 \%}$ & $20 \%$ \\
\hline Q3e & The emphasis focused on important topics & $0 \%$ & $9 \%$ & $31 \%$ & $\mathbf{4 5 \%}$ & $14 \%$ \\
\hline Q3f & The clinical applications seemed relevant \& appropriate & $0 \%$ & $3 \%$ & $20 \%$ & $\mathbf{5 8 \%}$ & $20 \%$ \\
\hline Q3g & The content was too comprehensive & $6 \%$ & $17 \%$ & $\mathbf{4 6 \%}$ & $23 \%$ & $9 \%$
\end{tabular}

Equally so, students agreed that as a 2D experience, it was a less valuable learning tool than a $3 \mathrm{D}$ experience $(60 \%$ agree/strongly agree), in that with $2 \mathrm{D}$ it is difficult to appreciate the layering in a structure.

\section{Themes 4 \& 5: Perceived outcomes of having attended the online lab}

The results in Table 4 suggest a majority of respondents believed that the online labs increased their understanding ( $77 \%$ agree/strongly agree), ability to apply knowledge (57\% agree/strongly agree) and reflection of learning (63\% agree/strongly agree). However, the respondents did not appear to believe that the online lab stimulated them to discuss the concepts and knowledge in their groups (44\% disagree/strongly disagree).

Table 4: As a result of having used the online lab

\begin{tabular}{|c|c|c|c|c|c|c|}
\hline & \multicolumn{3}{|c|}{ Strongly disagree } & \multicolumn{2}{|c|}{ Strongly agree } \\
\hline & & 1 & 2 & 3 & 4 & 5 \\
\hline Q4a & I was stimulated to reflect on anatomical concepts & $0 \%$ & $9 \%$ & $29 \%$ & $46 \%$ & $17 \%$ \\
\hline Q4b & $\begin{array}{l}\text { My intention to better understanding of anatomy was } \\
\text { achieved }\end{array}$ & $3 \%$ & $9 \%$ & $11 \%$ & $57 \%$ & $20 \%$ \\
\hline Q4c & $\begin{array}{l}\text { I was stimulated to discuss anatomical concepts with } \\
\text { those in my online group }\end{array}$ & $9 \%$ & $35 \%$ & $29 \%$ & $18 \%$ & $9 \%$ \\
\hline Q4d & $\begin{array}{l}\text { My application of anatomical knowledge to solve clinical } \\
\text { problems improved }\end{array}$ & $6 \%$ & $6 \%$ & $30 \%$ & $36 \%$ & $21 \%$ \\
\hline
\end{tabular}

Table 5: Regarding the overall learning experience of the online laboratory

\begin{tabular}{|l|l|c|c|c|c|c|}
\cline { 3 - 7 } \multicolumn{2}{c|}{} & Strongly disagree & \multicolumn{3}{c|}{ Strongly agree } \\
\hline Q5a & It provided valuable insights & $\mathbf{1}$ & $\mathbf{2}$ & $\mathbf{3}$ & $\mathbf{4}$ & $\mathbf{5}$ \\
\hline Q5b & $\begin{array}{l}\text { The online lab helped me understand anatomy form } \\
\text { multiple perspectives }\end{array}$ & $0 \%$ & $12 \%$ & $12 \%$ & $\mathbf{5 6 \%}$ & $21 \%$ \\
\hline Q5c & $\begin{array}{l}\text { The online lab enhanced my ability to interpret anatomy } \\
\text { rather than merely describe it }\end{array}$ & $3 \%$ & $3 \%$ & $30 \%$ & $\mathbf{4 1 \%}$ & $21 \%$ \\
\hline
\end{tabular}


Overall, shown in Table 5, the learning experience provided valuable insights (76\%), it helped enable them to understand anatomy from multiple perspectives $(62 \%)$, and enhanced their ability to interpret anatomy rather than merely describe it (79\%).

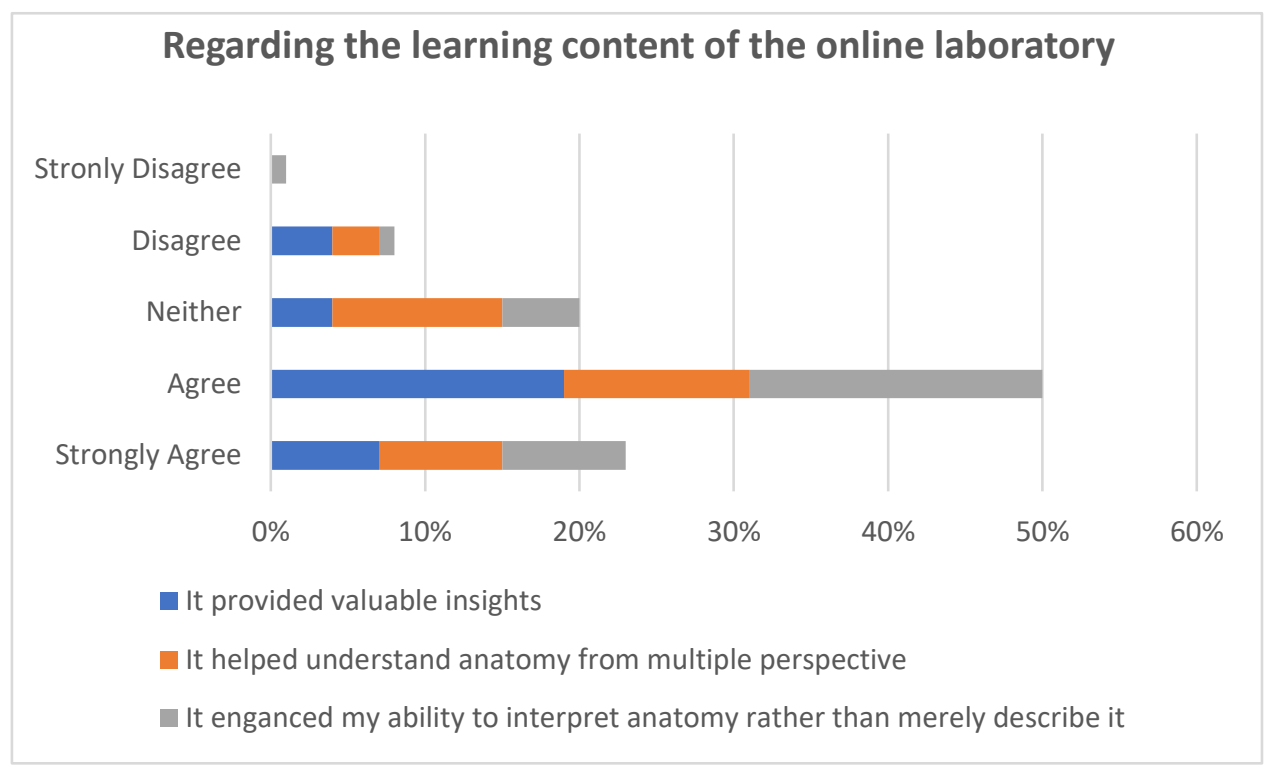

Figure 1: Student Perceptions of the Learning Content of the online laboratory

Survey respondents indicated that the videos (Acland's Atlas of human anatomy) embedded in each laboratory session enhanced the ability to present multiple points of view of gross anatomy (Figure 1). This teaching tool enhances the presentation of structures that are 3-dimentional in nature and equally with their relationships to each other.

Table 6: Academic Performance

\begin{tabular}{|l|l|l|l|l|}
\hline & 2019 semester 1 & 2019 semester 2 & 2020 semester 1 & 2020 semester 2 \\
\hline & RBM1100 & RBM1200 & RBM1100 & RBM1200 \\
\hline Mean +/-SD & $74.17+/-8.9$ & $76.49+/$ - SD 9.4 & $76.49+/-9.37$ & $75.98+/-9.23$ \\
\hline
\end{tabular}

There was no statistically significant difference in academic performance when comparing unit performance of RBM1100 and RBM1200 between semesters of the same year (2020) and that with the same unit's pre-COVID-19 year 2019. 

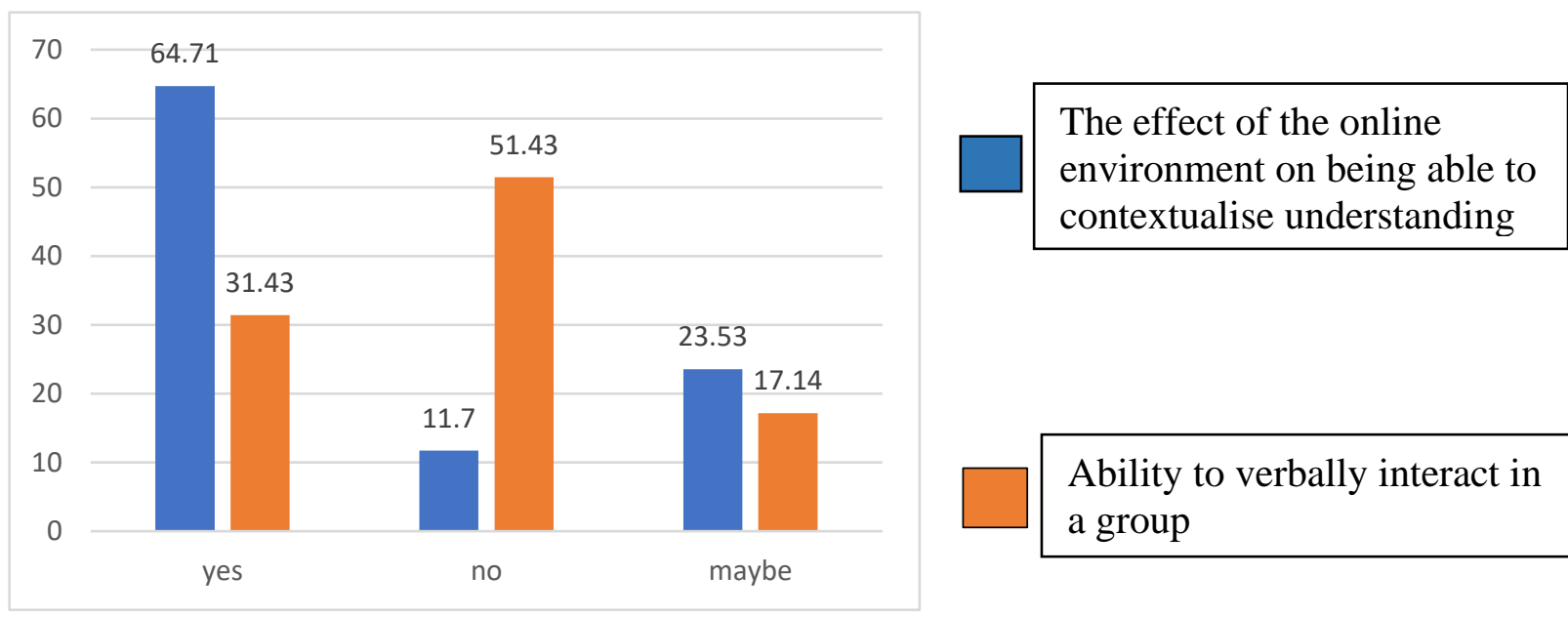

\section{Figure 2: The effect of the online environment on contextualising understanding and ability to verbally interact (\% of respondents)}

The survey results show the effect of the online environment on being able to contextualise understanding, and the ability to verbally interact in a group (Figure 2). While 64\% agreed that they could contextualise their understanding online, the majority said that the online environment was not helpful with being able to verbally interact within their group (Figure 2). Data is presented as \% of respondents.

\section{Open ended textual responses}

Respondents were given the opportunity to respond to an open-ended question, the results of which are presented in Table 7 below. Example written comments from the student feedback open-ended question "From the questions within the themes listed, which are the most important factors that contributed to your learning?" are presented.

Table 7: Summary of textual responses from survey

\begin{tabular}{|l|l|l|}
\hline Themes & Definition & Examples \\
\hline $\begin{array}{l}\text { The online } \\
\text { laboratory } \\
\text { learning } \\
\text { environment }\end{array}$ & $\begin{array}{l}\text { does the online environment make an } \\
\text { important contribution to my learning, is } \\
\text { it conducive to my learning, do the digital } \\
\text { aids help with the learning, is it an } \\
\text { challenging environment to learn in, and } \\
\text { are real bodies needed to appreciate the } \\
\text { relationship between structure and } \\
\text { function and more interesting to work } \\
\text { with. }\end{array}$ & $\begin{array}{l}\text { lab makes an important contribution } \\
\text { to my learning, it was logically } \\
\text { organised and appropriate for each } \\
\text { session, \& ease in locating } \\
\text { information }\end{array}$ \\
& $\begin{array}{l}\text { Not using real bodies makes it hard } \\
\text { to appreciate the relationship } \\
\text { between structure and function }\end{array}$ \\
& $\begin{array}{l}\text { Online is not that great } \\
\text { Lack of physical engagement with } \\
\text { real bodies in order to translate } \\
\text { theory into reality } \\
\text { The fact that we were learning online } \\
\text { and not from real bodies was less } \\
\text { interesting and engaging }\end{array}$ \\
\hline
\end{tabular}




\begin{tabular}{|c|c|c|}
\hline $\begin{array}{l}\text { The online } \\
\text { laboratory tutor }\end{array}$ & $\begin{array}{l}\text { This section focused on the contribution } \\
\text { of the tutor, how important was it that } \\
\text { they emphasized the key ideas \& } \\
\text { concepts, were they essential to interpret } \\
\text { their understanding of the structure } \\
\text { presented, \& how important were they in } \\
\text { providing feedback, \& as preferred to } \\
\text { independent self-directed study }\end{array}$ & $\begin{array}{l}\text { - 'tutor feedback is very important' } \\
\text { - 'The online anatomy lab complements } \\
\text { the anatomy workshop teaching } \\
\text { program and the tutor is key to } \\
\text { understanding the structures } \\
\text { presented' } \\
\text { 'with tutor explaining key ideas and } \\
\text { concepts also high' } \\
\text { 'Overall, the online learning } \\
\text { experience with the tutor is better than } \\
\text { independent self-directed learning' }\end{array}$ \\
\hline $\begin{array}{l}\text { While in the } \\
\text { online } \\
\text { laboratory itself }\end{array}$ & $\begin{array}{l}\text { This section related to whether the } \\
\text { learning experience was engaging, \& in } \\
\text { helping their understanding, was the } \\
\text { experience less valuable being in } 2 \mathrm{D} \& \\
\text { not in } 3 \mathrm{D}, \& \text { how comprehensive was the } \\
\text { learning experience }\end{array}$ & $\begin{array}{l}\text { - 'More manageable to focus on one } \\
\text { - 'I cabject at a time' } \\
\text { - 'Despite not doing science in VCE I } \\
\text { was able to achieve HD's...' }\end{array}$ \\
\hline $\begin{array}{l}\text { The perceived } \\
\text { learning } \\
\text { experience after } \\
\text { having attended } \\
\text { the online } \\
\text { anatomy lab }\end{array}$ & $\begin{array}{l}\text { This section related to whether the lab } \\
\text { experience stimulated the students to } \\
\text { reflect on anatomical concepts, whether } \\
\text { it had the outcome of producing better } \\
\text { understanding of anatomy, the ability to } \\
\text { discuss anatomical concepts with those in } \\
\text { their online group, and whether it } \\
\text { allowed the application of anatomical } \\
\text { knowledge to solve clinical problems. }\end{array}$ & $\begin{array}{l}\text { - '[Teacher] is very mindful of the } \\
\text { students and reassures us. Such a } \\
\text { relief that an expert in the field has the } \\
\text { heart to reassure us and act as a } \\
\text { supportive voice.' } \\
\text { 'Clear, communicative, understands } \\
\text { the needs of first year students, } \\
\text { engaging, humorous, knows the } \\
\text { material well.' }\end{array}$ \\
\hline $\begin{array}{l}\text { The overall } \\
\text { perceived gain } \\
\text { learning as a } \\
\text { result of } \\
\text { attending the } \\
\text { online } \\
\text { laboratory }\end{array}$ & $\begin{array}{l}\text { Elements related to how it provided } \\
\text { valuable insights, to understand anatomy } \\
\text { from multiple perspective, and whether it } \\
\text { enhanced the student's ability to interpret } \\
\text { anatomy rather than merely describe it. }\end{array}$ & $\begin{array}{l}\text { - '[Teacher] is very mindful of the } \\
\text { students and reassures us. Such a } \\
\text { relief that an expert in the field has the } \\
\text { heart to reassure us and act as a } \\
\text { supportive voice.' } \\
\text { 'Clear, communicative, understands } \\
\text { the needs of first year students, } \\
\text { engaging, humorous, knows the } \\
\text { material well.' }\end{array}$ \\
\hline
\end{tabular}

Overall, the comments in Table 7 are consistent with the findings of the survey. For the most part, respondents were positive about the online lab experience, but believed that having access to cadavers in a class laboratory setting would have provided for a richer overall experience.

\section{Discussion}

The COVID-19 pandemic has, and continues to have a profound effect on higher education. Students and teachers needed to quickly embrace new technologies, adapt their learning and teaching styles to be effective within these new technologies, and change the way they connect with students to ensure their education could continue. The usual peer-to-peer social engagement, in which cues such as facial expressions that promote connectivity, passion and inspiration to help the learning process, was significantly marginalised.

This study demonstrates from both quantitative and qualitative data that students' overall perception of their online learning experience (Figure 1) in topographical anatomy laboratory was positive and that it had extended their learning. They expressed appreciation of the teaching staffs' efforts online and in being allowed to continue their studies through the COVID-19 pandemic, as it resulted in less disruption of their progression through their course. While peer-to-peer social interaction was not possible during the teaching and learning 
sessions, new as yet unidentified substitute interactions developed. These included limited group interactions within breakout rooms, as well as the development of occasional outside formal Zoom class time, online private discussion forums.

While much of the evidence available suggests that moving to online teaching from in-class teaching was not received well by students (Chen, Kaczmarek, Ohyama, 2020; Pather et al., 2020), some evidence suggests that students were generally satisfied with the online course and that many of them preferred the online course to the offline course (Kim et al., 2020). Kim et al.'s (2020) results suggested a majority (84\%) of the students wanted to maintain the online course after the end of COVID-19 (Kim et al., 2020). While the students in this study were satisfied with the quality of instruction provided, and achieved similar academic outcomes to face-to-face students in previous years, the students in this study stated that they would have preferred face-to-face laboratory classes over the remote Zoom classroom format.

While there are many benefits of studying online digital anatomy as a replacement of the cadaver-based learning format, such as allowing students to continue with their studies, there was less travel to and from the institution, and more immediate accessibility. Also, it was possible to learn at any time and from anywhere, provided that there is adequate internet access. Online learning allows for greater learner-oriented learning flexibility, students are less distracted, can study at their own pace and repeat tasks such as listening to, or watching lectures as many times as they want, thereby enabling them to modulate their learning pace according to their ability.

\section{Challenges for both staff and students}

Within very tight time lines, it proved challenging to prepare new course content that would maintain learning outcomes, assessment standards, and without a negative impact on graduate capabilities. We believe that the online learning platform Zoom, in the format in which we conducted them, proved, for most, to be an adequate substitute.

The quality of the delivery of online gross anatomy laboratories was heavily reliant on the style of teaching provided by the educators and demonstrators as frequently expressed by students. Educators had to prepare content delivery in various forms to convey an appreciation for the intricacy of the subject and establish comprehension, which was not always immediately clear to students, and through consistent feedback from students, developed into a form that became more user friendly.

The use of various multimedia forms (digital cadaver image, dissection Video, interactive computer based programs such as An@tomedia)were employed simultaneously to encompass multiple perspectives and provide a broader picture in order to develop students' understanding of the regions or structures being studied, as the 2-dimensional limitations of each individual resource did not accurately convey the multi-dimensional complexity of the many layers within the human body, which was commented by students as being a significant limitation to their learning. Anatomy is a 3-dimentional subject that requires the development of an understanding of the 3-dimentional relationships between structures, so often achieved with the study of human cadaveric materials or models.

The adaptation of the curriculum into online gross anatomy laboratory classes was a direct result of the impact of the COVID-19 pandemic, and the subsequent restrictions rendered on face-to-face teaching capabilities. The content was developed with the key objective to 
temporarily provide a substitute, filling the void forged by an inability for the students and teaching staff to access the human cadaveric specimens. Based on our students' feedback it certainly fulfilled this task. This observation is supported by Longhurst et al. (2020), based on data collected from 14 Universities in the United Kingdom and Republic of Ireland. Indeed, the value or effectiveness of various teaching approaches used in the anatomy laboratory have been controversial and ongoing due to a general lack of methodological weaknesses and lack of summative empirical data (Wilson et al., 2018). Wilson et al. (2018), based on a metaanalysis, concluded that "student performance on knowledge examinations was equivalent regardless of being exposed to either dissection or another laboratory instructional strategies such as dissection vs. prosection, dissection vs. digital media, dissection vs. models/modelling, and dissection vs. hybrid and therefore in the context of short-term knowledge gains alone, dissection is no better, and no worse, than alternative instructional modalities"(pp.122-123), an observation supported in this study.

Students' academic performance also did not differ significantly compared with previous years, an observation supported by others (Kim et al., 2020), but not supported by Mathiowitz, Yu, and Quake-Rapp (2016), who demonstrated that students in the in-person format had better academic results compared with distance learning. Our observations and students' feedback suggest however, that the online space is a more difficult environment to work in. The online learning environment using the platform Zoom has significant limitations, where the user has no control over power failures or inadequate internet access, or of insufficient quality in computer equipment from both the student and teacher.

It seems that while we can achieve cognitive engagement in the laboratory, as academic outcomes have remained the same, it does come at a cost of social engagement. The online environment is less than conducive to learning in the form of promoting group work, in engaging with others either by facilitating discussion or verbal communication in general with other members in online groups. The survey indicates that students are able to contextualise their understanding, but are less able to work in a group and to verbally describe anatomic concepts (Figure 2). It is socially more isolating, as cameras can be turned off and it is harder to verbally communicate and connect online with each other and teaching staff.

While distance-learning pedagogy would suggest that harnessing the collaborative and interactive functions now available and built into online communication platforms is possible, from our feedback it did not harness or promote the development of social engagement during the teaching process. Indeed, there was clear preference for live streaming tutor support and connectivity. Other factors, such as not using real bodies, made it hard to appreciate the 3D relationship between structure and function. The online laboratory was perceived as less interesting and engaging, not as engaging in group work (breakout rooms), nor did it stimulate students to discuss anatomical concepts with those in their online group. While the online gross anatomy laboratory model was an adequate substitute, it was found to fall short of the standard of comprehension generally provided by the face-to-face delivery of on-campus wet laboratory classes. However, irrespective of what teaching approach is used, whether face-to-face or online, we found that similar learning outcomes were achieved. This observation is not supported by Mathiowitz et al. (2015), who showed that the in-person experience produced better academic outcomes. In contrast Wilson (2018) showed that dissection provided no significant advantages or disadvantages, than alternative instructional modalities (Wilson et al., 2018) 
It is without doubt that the future of cadaver-based anatomy education is certainly under review, as the human body donor program has been suspended in many parts of Australia and around the world, and the potential risks of infection from COVID-19 infected cadavers remains unexplored and a high-risk environment (Lemos, et al., 2020; Onigbinde et al., 2020). Currently, at a time when social distancing measures are isolating students from family and friends, maybe in the future when a return to normal is possible it will be more important than ever to provide a sense of community in our teaching, embracing a higher awareness of the benefits of both cognitive and social engagement in our classroom.

\section{Conclusions}

Student perception of online learning as replacement for the traditional gross anatomy laboratory was surprisingly positive. Most students agreed that as a visual learning resource, it provided valuable perspectives, improved understanding of anatomy and helped with the application of anatomical knowledge. Equally so, they strongly agreed that the online 2D learning experience was less engaging and interesting than learning in $3 \mathrm{D}$ using cadavers.

We believe that the future delivery of classes could be altered to encompass and include greater use of the online platforms, but the student experience of the human cadaveric specimens are essential to the teaching and learning of this subject.

\section{Limitations and future directions}

One limitation of this study is its small sample size. It would be useful to see if the conclusions remain the same had the sample size been larger. The assessment procedure used is also an important limitation in the delivery context. Moving away from in-person paper-based assessment to the online environment, with limitations placed on invigilation and increased difficulty by students to respond with labelling by computer keyboard, makes comparison between cohorts difficult. However, as results were similar across 2019 and 2020, this would indicate that perhaps the blended design itself contributes towards student active learning.

A further significant limitation is that the students providing the feedback have no other point of comparative reference other than the experience they were currently in. It would be interesting to follow this group of students and compare their experience once they are able to return to the anatomy laboratory. In addition, a further limitation is that our focus was on young adults with low prior knowledge. It would be useful to examine how these principles apply to other age groups and types of learners, and those who are less technologically competent. Also, although our focus was on laboratory-based lessons in STEM domains, it would be useful to determine how the principles apply in other discipline domains.

\section{Acknowledgements}

The authors thank Mr Ethen Kauiers, who assisted with the laboratory worksheet development for this study.

\section{Disclosures}

No conflicts of interest, financial or otherwise, are declared by the authors.

\section{References}

Acland, R. (2013). Acland's Video Atlas of Human Anatomy ${ }^{\circledR}$. Wolters Kluwer Health, Inc., Philadelphia, PA. URL: https://aclandanatomy.com/ [accessed 10 April 2020]. 
Ali, W. (2020). Online and remote learning in higher education institutes: A necessity in light of COVID-19 pandemic. Higher Education Studies, 10(3), 16-25.

Attardi, S. M., \& Rogers, K. A. (2015). Design and implementation of an online systemic human anatomy course with laboratory. Anatomical sciences education, 8(1), 53-62. https://doi.org/10.1002/ase.1465

Burki, T. K. (2020). COVID-19: Consequences for higher education. The Lancet Oncology, 21(6), 758.

Chen, E., Kaczmarek, K., \& Ohyama, H. (2020). Student perceptions of distance learning strategies during COVID-19. Journal of dental education, 10.1002/jdd.12339. Advance online publication. https://doi.org/10.1002/jdd.12339

Drake, R. L., Vogl, A. W., \& Mitchell, A. W. (2019). Gray's Anatomy for Students 4th Edition.

Eizenberg, N., Briggs, C., Barker, P., \& Grkovic, I. (2019). an@ tomedia. [Database]. Retrieved from http://www.anatomediaonline.com.

Evans, D., Bay, B. H., Wilson, T. D., Smith, C. F., Lachman, N., \& Pawlina, W. (2020). Going Virtual to Support Anatomy Education: A STOPGAP in the Midst of the Covid-19 Pandemic. Anatomical sciences education, 13(3), 279-283. https://doi.org/10.1002/ase.1963

Flynn, W., Kumar, N., Donovan, R., Jones, M., \& Vickerton, P. (2021). Delivering online alternatives to the anatomy laboratory: Early experience during the COVID-19 pandemic. Clinical anatomy (New York, N.Y.), 34(5), 757-765. https://doi.org/10.1002/ca.23722

Ganske I., Su T., Loukas M. \& Shaffer, K. (2006). Teaching methods in anatomy courses in North American medical schools: the role of radiology. Academic Radiology, 13:1038-1046

Gilroy, A. M., McPherson, B. R., Ross, L. M., Schuenke, M., Schulte, E., U., S., \& Baker, E. W. (2019). Thieme Teaching Assistant [Database]. Retrieved from https://www.thieme.com.

Government of Victoria (1982). Human Tissue Act (1982), authorised version No. 044 / No.9860 of 1982. https://www.legislation.vic.gov.au/in-force/acts/human-tissue-act-1982/044

Hubbard, C. J., Miller, J. S., \& Olson, D. (2005). A new way to teach an old topic: The cadaver-based anatomy short course for high school students. Anatomical Record - Part B New Anatomist, 284(1), 6-11. https://doi.org/10.1002/ar.b.20059

Iwanaga, J., Loukas, M., Dumont, A. \& Tubbs RS. (2020). A review of anatomy education during and after the COVID-19 pandemic: Revisiting traditional and modern methods to achieve future innovation. Clinical Anatomy, 2020:1-7. https://doi.org/10.1002/ca.23655

Kim, J. W., Myung, S. J., Yoon, H. B., Moon, S. H., Ryu, H., \& Yim, J-J. (2020). How medical education survives and evolves during COVID-19: Our experience and future direction. PLoS ONE, 15(12). https://doi.org/10.1371/journal.pone.0243958

Klein, R., Sinnayah, P., Kelly, K., Winchester, M., Rajaraman, G., \& Eizenberg, N. (2019). Utilising computer based learning to complement class teaching of gross anatomy. International Journal of Innovation in Scienceand Mathematics Education, 27(8), 10-25.

Larkin, T.A. \&McAndrew, D.J. (2013). Factors influencing students' decisions to participate in short "dissection experience" within a systemic anatomy course. Anatomical Sciences Education 6(04):225-231

Lemos, G. A., Araújo, D. N., de Lima, F., \& Bispo, R. (2021). Human anatomy education and management of anatomic specimens during and after COVID-19 pandemic: Ethical, legal and biosafety aspects. Annals of anatomy = Anatomischer Anzeiger: official organ of the Anatomische Gesellschaft, 233, 151608. https://doi.org/10.1016/j.aanat.2020.151608

Longhurst, G. J., Stone, D. M., Dulohery, K., Scully, D., Campbell, T., \& Smith, C. F. (2020). Strength, Weakness, Opportunity, Threat (SWOT) Analysis of the Adaptations to Anatomical Education in the United Kingdom and Republic of Ireland in Response to the Covid-19 Pandemic. Anatomical sciences education, 13(3), 301-311. https://doi.org/10.1002/ase.1967

Mathiowetz, V., Yu, C. H., \& Quake-Rapp, C. (2016). Comparison of a gross anatomy laboratory to online anatomy software for teaching anatomy. Anatomical sciences education, 9(1), 52-59. https://doi.org/10.1002/ase.1528

Mayer, R.E. Designing Multimedia Instruction in Anatomy: An Evidence-Based Approach (2020) Clinical Anatomy, 33:2-11.

Mayer, R.E., Fiorella, L. \& Stull, A. (2020) Five ways to increase the effectiveness of instructional video. Education Tech Research Dev 68, 837-852. https://doi.org/10.1007/s11423-020-09749-6

McCluskey, T., Weldon, J., \& Smallridge, A. (2019). Rebuilding the first year experience, one block at a time. Student Success, 10(1), 1-15. doi:https://doi.org/10.5204/ssj.v10i1.1148

McCluskey, T., Smallridge, A., Weldon, J., Loton, D., Samarawickrema, G. \& Cleary, K. (2020). Building on the VU Block foundations: Results from the inaugural first year cohort. In E. Heinrich and R. Bourke (Eds.), Research and Development in Higher Education: Next generation, Higher Education: Challenges, Changes and Opportunities, 42 (pp $61-72$ )

McLachlan, J. C., Bligh, J., Bradley, P., \& Searle, J. (2004). Teaching anatomy without cadavers. Medical education, 38(4), 418-424. https://doi.org/10.1046/j.1365-2923.2004.01795.x 
Morris J.F., Chirculescu A.R.M. (2007). Structure and assessment of a short intense clinical anatomy course shortly before clinical studies. European Journal of Anatomy, 11(1):95-98

Onigbinde, O. A., Ajagbe, A. O., Oyeniran, O. I., \& Chia, T. (2020). Post-COVID-19 pandemic: Standard operating procedures for gross anatomy laboratory in the new standard. Morphologie: bulletin de l'Association des anatomistes, S1286-0115(20)30093-X. Advance online publication. https://doi.org/10.1016/j.morpho.2020.10.004

Thompson, A. R., \& Marshall, A. M. (2020). Participation in dissection affects student performance on gross anatomy practical and written examinations: Results of a four-year comparative study. Anatomical sciences education, 13(1), 30-36.

UNESCO. (2020). United Nations Educational, Scientific and cultural Organisation. COVID-19 educational disruption and response. UNESCO, Paris, France. Url: https://en.unesco.org/themes/educationalemergencies/coronavirus-school-closures

Pather, N., Blyth, P., Chapman, J. A., Dayal, M. R., Flack, N., Fogg, Q. A., Green, R. A., Hulme, A. K., Johnson, I. P., Meyer, A. J., Morley, J. W., Shortland, P. J., Štrkalj, G., Štrkalj, M., Valter, K., Webb, A. L., Woodley, S. J., \& Lazarus, M. D. (2020). Forced Disruption of Anatomy Education in Australia and New Zealand: An Acute Response to the Covid-19 Pandemic. Anatomical sciences education, 13(3), 284-300. https://doi.org/10.1002/ase.1968

Pather, N. (2015). Teaching Anatomy: prosections and dissections. In: Teaching Anatomy: A Practical Guide, Chan, L., Pawlina W. Cham, (Eds). Switzerland: Springer, 2015.

Primal-Pictures. (2019). Anatomy.TV. [Database] In Retrieved from https://primalpictures.com.

Wilson, A. B., Miller, C. H., Klein, B. A., Taylor, M. A., Goodwin, M., Boyle, E. K., Brown, K., Hoppe, C., \& Lazarus, M. (2018). A meta-analysis of anatomy laboratory pedagogies. Clinical anatomy (New York, N.Y.), 31(1), 122-133. https://doi.org/10.1002/ca.22934 